\title{
Advances on Microwave Ceramic Filters for Wireless Communications (Review Paper)
}

\author{
Stelios Tsitsos \\ Department of Computer Engineering, Technological and Educational Institute of Central Macedonia, Greece
}

\begin{tabular}{|c|c|}
\hline Article Info & ABSTRACT \\
\hline Article history: & \multirow{4}{*}{$\begin{array}{l}\text { A review of the technological developments on ceramic monoblock filters } \\
\text { and duplexers over the years is presented in this work. Early designs based } \\
\text { on simulated and measured data are presented along with later designs based } \\
\text { on accurate equivalent circuits as well as the use of evolution algorithms for } \\
\text { optimal design. }\end{array}$} \\
\hline Received Nov 8, 2017 & \\
\hline Revised Feb 4, 2018 & \\
\hline Accepted Jul 12, 2018 & \\
\hline
\end{tabular}

\section{Keyword:}

CAD

Ceramic filters

Dielectric filters

Duplexers

Wireless communications

Copyright (C) 2018 Institute of Advanced Engineering and Science. All rights reserved.

\section{Corresponding Author:}

Stelios Tsitsos,

Department of Computer Engineering,

Technological and Educational Institute of Central Macedonia,

Magnesias End, Serres GR-62124, Greece.

Email: s.tsitsos@teicm.gr

\section{INTRODUCTION}

Microwave filters and duplexers play an important role in wireless communications by rejecting unwanted signals in the frequency band(s) of interest. Several planar-type structures have been presented in recent years [1], [2], [3], [4]. Although they provide low insertion loss in the passband and sharp rejection in the stop band, these structures are not suitable for modern mobile handsets, tablets, notebooks etc., due to the relatively large area they occupy. Ceramic monoblock filters and duplexers on the other side provide high selectivity, temperature stability, compact size, low insertion loss and low cost [5], [6], [7]. Since the 1980's continuous advances in such components have resulted in miniaturised and inexpensive microwave filters suitable for mobile communications handsets as well as tablets, notebooks etc. for local area networks applications.

The use of ceramic monoblock filters and duplexers really took off in the 1990's and 2000's with the vast growth of mobile communications all over the world. The need for even smaller mobile handsets led to the extensive research and development of miniaturised filters and duplexers by a large number of Researchers, Academic Institutes and Companies. The key technique for miniaturising these components is the use of high dielectric constant $(30<\varepsilon r<100)$ and low loss ceramic materials. The basic topology of these filters consists of adjacent dielectric resonators coupled to each other and to the I/O ports.

In this work an attempt has been made to review the technological advances made over the years on the design of ceramic monoblock filters and duplexers. Early designs were based on equivalent "general purpose" circuits found in the literature, and also on simulated and measured data. As a result the measured performance of these devices often departed from the desired specifications and a considerable amount of time was spent on re-designing, re-simulating and trimming. Later work was based on the extraction of more 
accurate equivalent circuits from first electromagnetic principles and also the use of evolution algorithms for optimal design.

\section{CERAMIC BLOCK FILTERS AND DUPLEXERS}

Early work started in Finland with the design of integrated miniature ceramic filters for $900 \mathrm{MHz}$ cellular mobile radio applications [8] utilising stripline TEM $\lambda / 4$ cavities with ceramic core. The design was based on models available in the literature, computer simulations and measurements of coupling coefficients for irregular structures. Interdigital and combline filter structures were fabricated using titanate based ceramic compounds with dielectric constants of 37 and 78 respectively as shown in Figure 1. After trimming the fabricated structures good agreement between simulated and measured results was established.
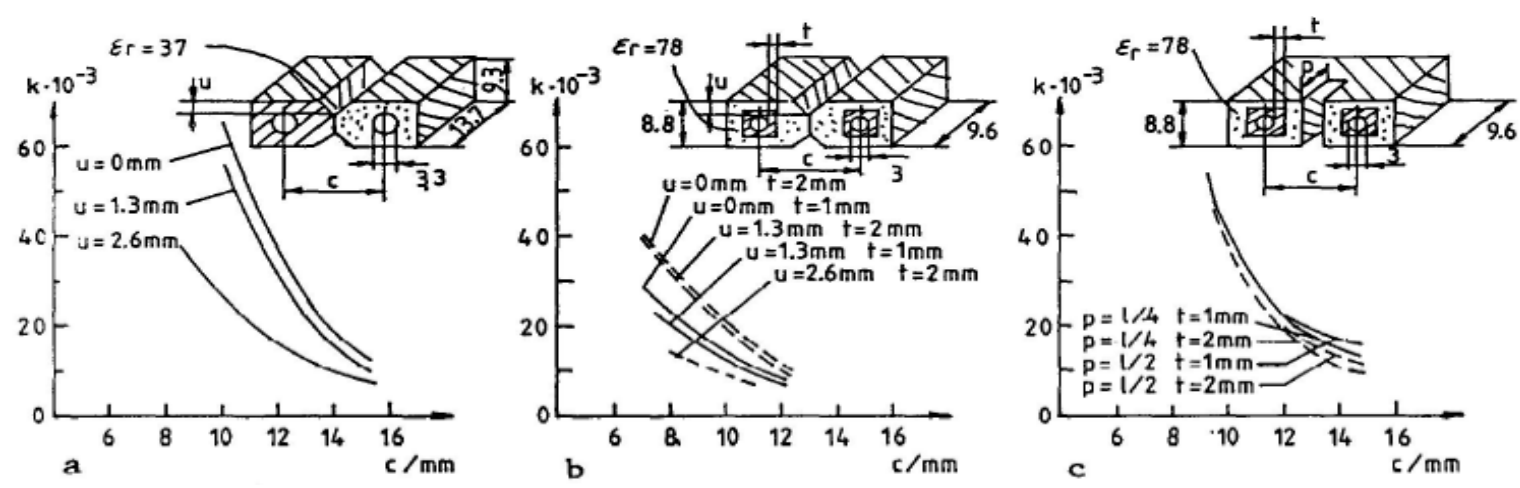

Figure 1. Measured coupling coefficients from symmetric resonator pairs without and with irregularities. (a) Interdigital with grooves. (b) Combline with grooves. (c) Combline with a cut [8].

At the same time Isota et al [9] of Mitsubishi Electric CompanyTM, Japan, designed and manufactured a combline ceramic filter with $\lambda / 4$ resonators operating at $1000 \mathrm{MHz}$ Figure 2 . The advantage of this filter was the suppression of the third harmonic where a second pass-band was observed. This was achieved by placing grooves on the outer surface of the dielectric block, which also provided enough interresonator coupling.
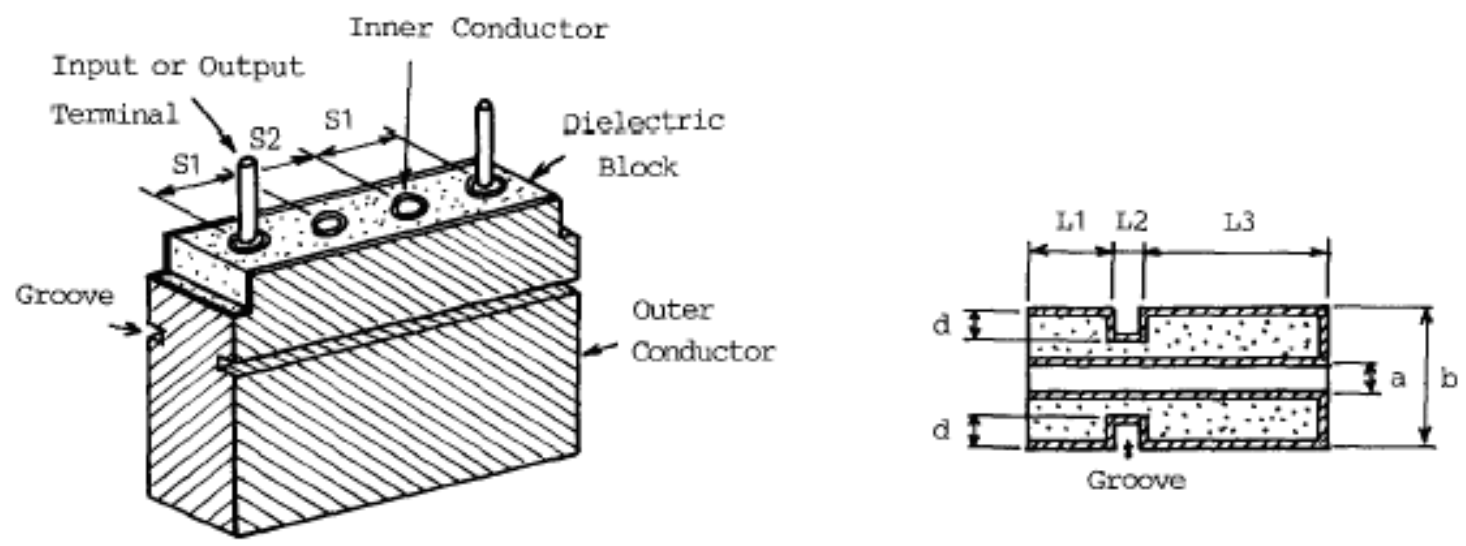

Figure 2. Monoblock dielectric filter configuration: (a) Monoblock dielectric filter,

(b) Filter cross-section [9].

The biggest expansion of the use of ceramic monoblock filters for mobile communications took place in the 1990's with the vast growth of mobile communications, due to the filters' small size and low cost. MurataTM, Japan, designed and manufactured a fully monoblock ceramic filter with a combline 
configuration for the $800 \mathrm{MHz}$ band cordless telephone system [10] and also a ceramic monoblock duplexer [11]. This filter consists of a high permittivity $(\varepsilon r=90)$ dielectric monoblock with multiple cylindrical holes which constitute the inner conductors of the resonators. All surfaces are metallised except the surrounding of the I/O ports and the circumferential gaps inside at the end of the cylindrical holes. This structure is shown in Figure 3(a) and the duplexer structure in Figure 3(b). The design of the filter was based on equivalent circuits available in the literature and 3D Finite Element Method analysis. The experimental and simulated results exhibit a difference of about $5 \%$.

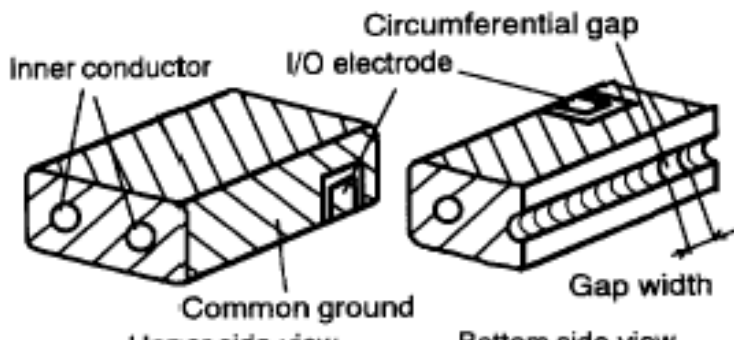

(a)

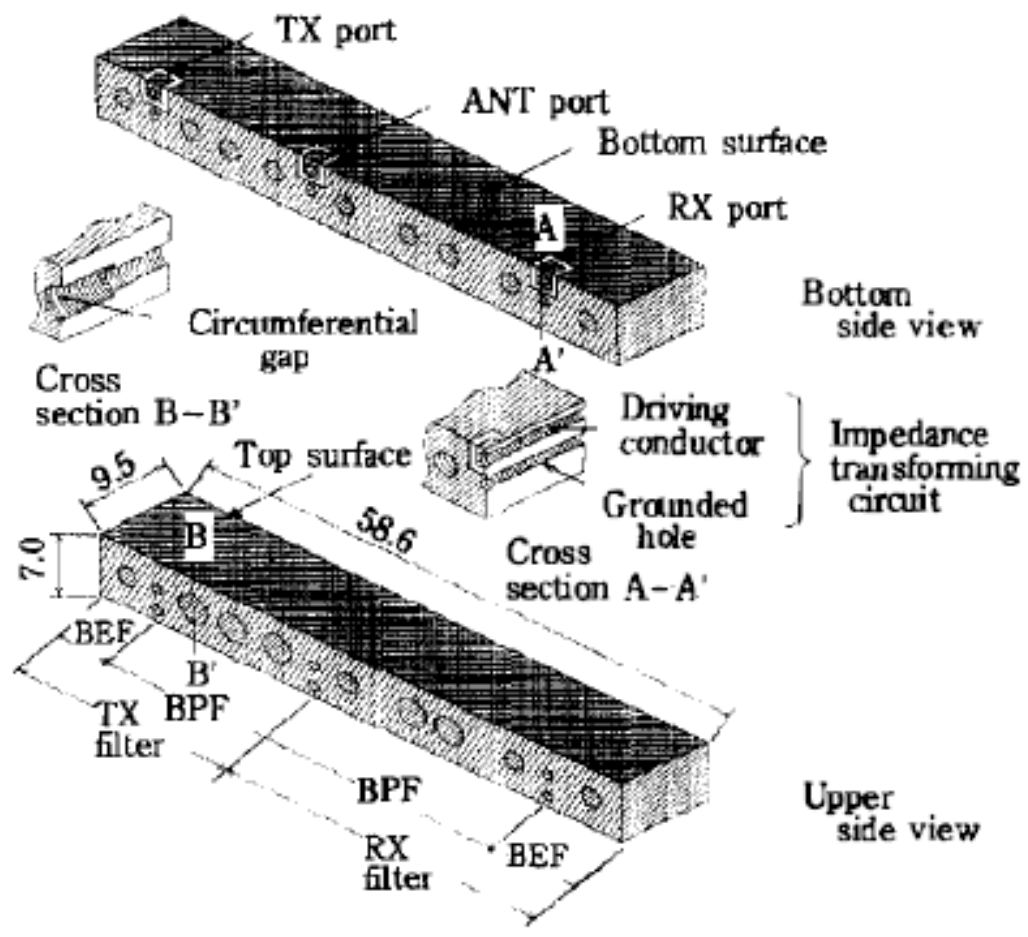

(b)

Figure 3. (a) Monoblock dielectric filter structure [10], (b) Monoblock dielectric duplexer structure [11].

Kennerley and Hunter [12] designed and manufactured ceramic stripline filters for mobile and wireless LAN's communications able to overcome the disadvantage of tuning (necessary to compensate for dimensional tolerances) often encountered with monoblock structures. These stripline filters consist of two tiles of ceramic substrate with a transmission line circuit printed on a thin, low permittivity substrate forming a sandwich structure Figure 4. The low permittivity substrate can be extended beyond the ceramic tiles to 
form the input and output terminals. Grounding is achieved by conductor coating the outside faces of the structure.

Kobayashi and Saito [13] of Sumitomo Metal IndustriesTM, Japan, designed and manufactured ceramic filters for cordless phone systems. These filters were constructed by placing stripline made of high permittivity ceramics $(\varepsilon r=90)$ between microstrip lines made of low permittivity ceramics $(\varepsilon r=15)$ Figure 5 to achieve additional miniaturisation. Some discrepancies were observed between simulated and measured results.

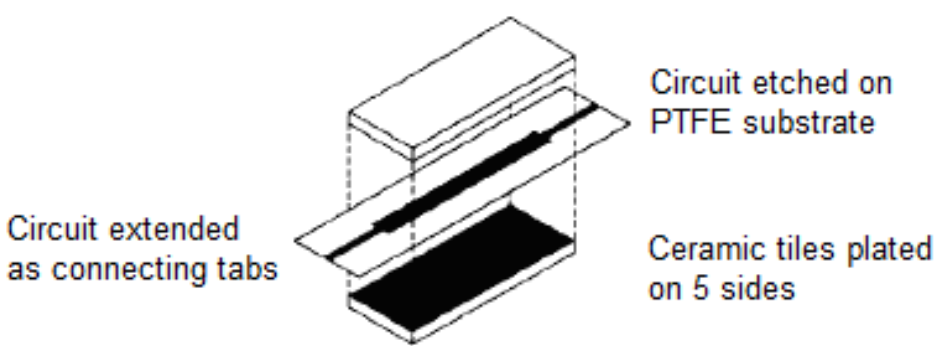

Figure 4. Ceramic stripline filter construction [12].

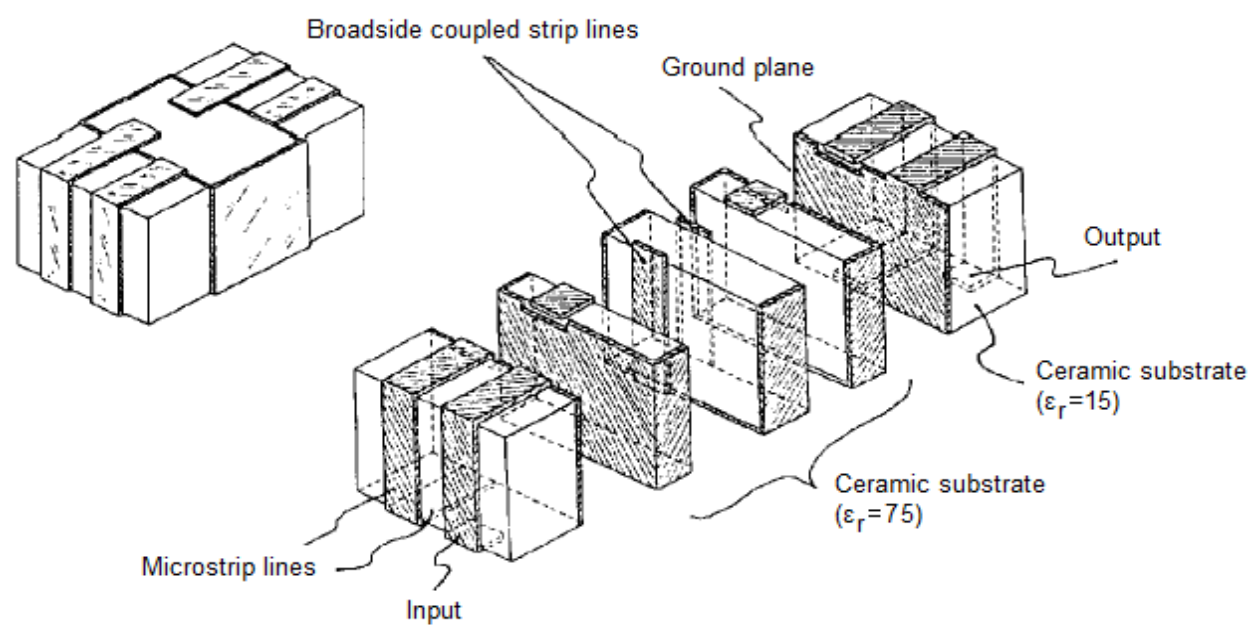

Figure 5. Miniaturised filter structure [13]

Ishikawa et al [14] of MurataTM, Japan, designed and manufactured planar dielectric resonator filters fabricated in ceramic substrates for millimetre wave applications. The advantage of these filters is that they can easily be integrated into planar circuits, such as MMICs and MICs. Figure 6(a) shows the configuration of a TE010 mode dielectric resonator. The resonator consists of a dielectric substrate and upper and lower metal plates. The dielectric substrate is placed between the metal plates. Both upper and lower surfaces of the substrate are metallised. Thin-film electrodes on both sides of the substrate have hollow patches of the same diameter. The electrodes divide the resonator into three regions to be cutoff against cylindrical TE mode, therefore, the electromagnetic field is concentrated within the circular hollow patches. Figure 6(b) represents the filter configuration.

In [15] a method for modelling ceramic comb-line filters was presented. This method considers a ceramic combline filter as a multi-conductor transmission line Figure 7 and extracts equivalent circuit parameters for transmission lines which in turn can easily be simulated by a circuit simulator. Although this method speeds up significantly the simulation process it is limited to uniform multi-conductor transmission lines only and cannot treat any irregular structures.

Park and Ziegert [16] published a feasibility study on producing ceramic block filters in small quantities. They used a capacitively coupled lumped element band-pass filter model from the literature and a generic ceramic structure to determine the unloaded $Q$ factor and frequency range Figure 8 . Then the filter frequency, order, and shape factor could be tailored with low cost tuning methods to implement the coupling 
coefficients and mesh resonances to achieve narrow band-pass coupled resonator filters. This was achieved with the use of automated milling or laser etching tools to modify the geometry of both the ceramic and plating and hence the cost of the generic structure and associated equipment was spread over many applications.

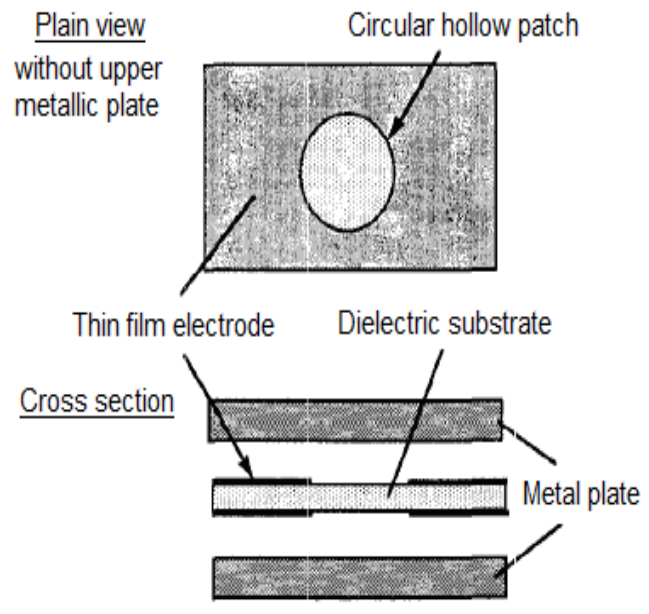

(a)

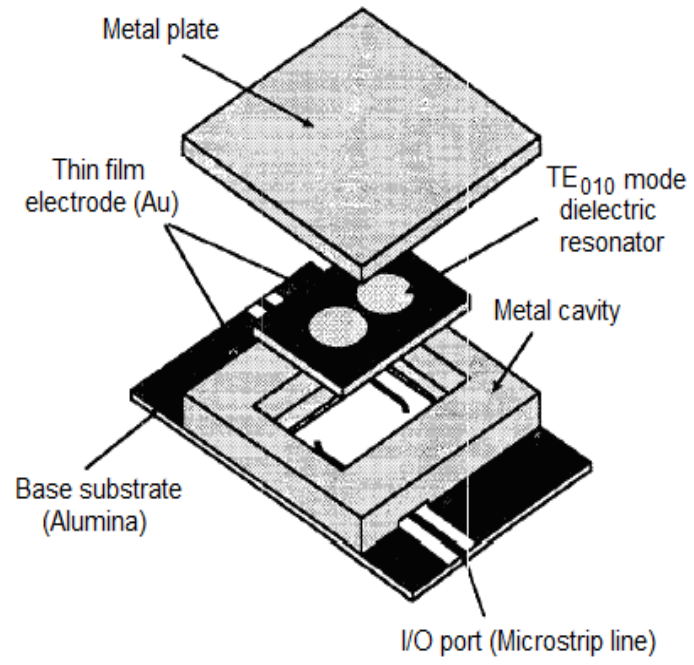

(b)

Figure 6. (a) TE010 mode dielectric resonator (b) Filter configuration based on TE010 mode dielectric resonator [14].

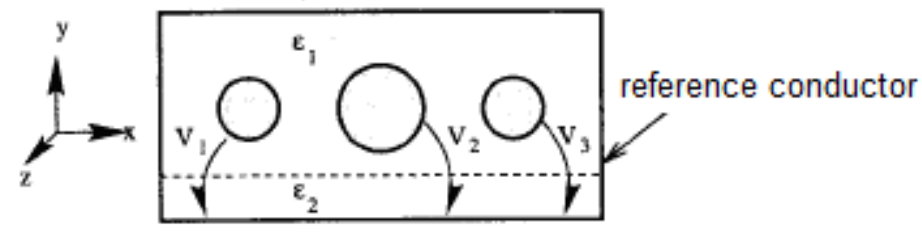

Figure 7. Multi-conductor transmission line [15].
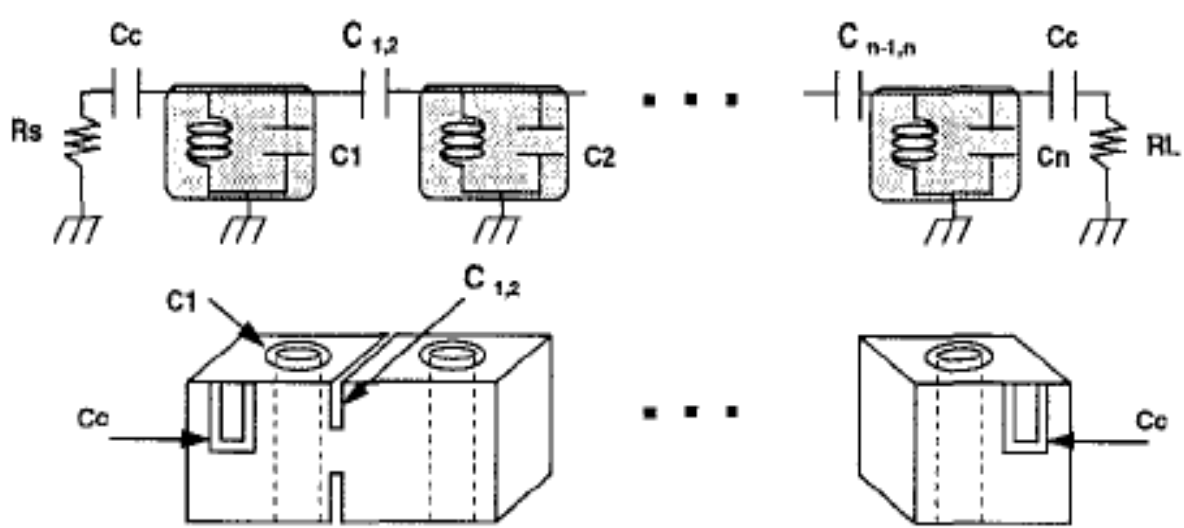

Figure 8. Ceramic block filter and its equivalent circuit model [16].

In [17] a helical ceramic resonator design was described and a sample filter structure based on this type of resonator was presented. The helical resonator structure was produced using standard ceramic 
resonator technology and led to substantial miniaturisation of the filters. This type of resonator and the associated filter are illustrated in Figures 9 and Figure 10.

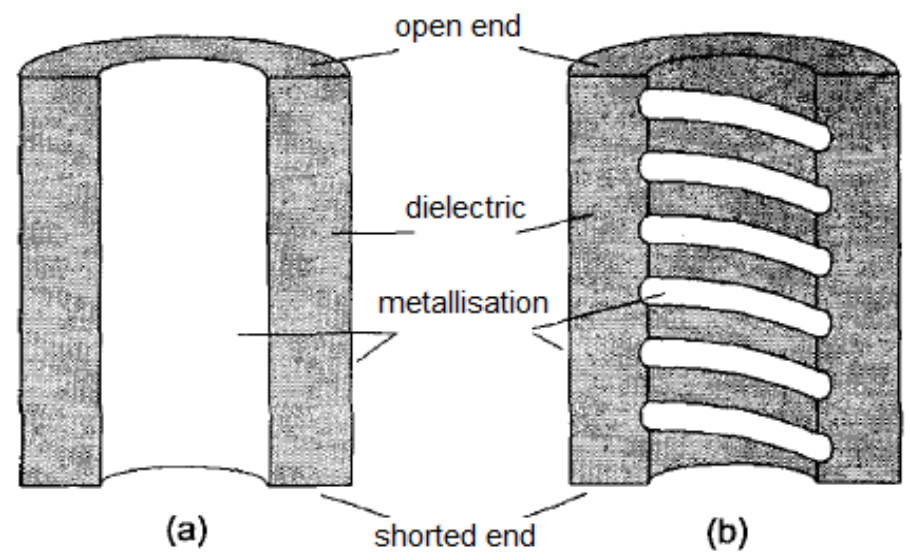

Figure 9. Cross-sectional view of two ceramic resonator structures: (a) conventional coaxial. (b) helical [17].

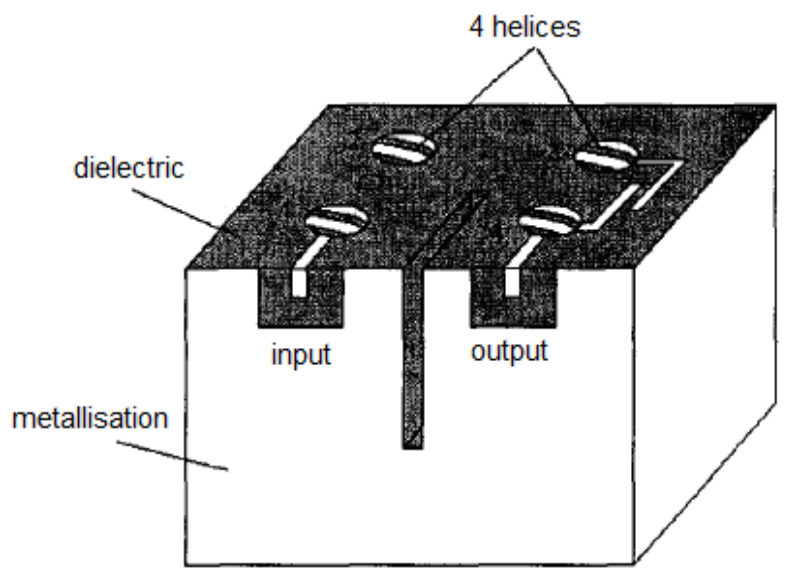

Figure 10. A generalised ceramic monoblock filter utilising 4 helical resonators [17]

\section{RESULTS AND DISCUSSION}

So far we have seen that the extraction of the equivalent circuit parameters for monoblock structures is usually performed using experimental and electromagnetic simulation data fitted to a basic topology equivalent model found in the literature with arbitrary initial values. This basic model is often limited and optimisation may result in unrealistic parameter values. Since 2004 Tsitsos et al and Kyriazidis et al produced an extensive work on ceramic monoblock filter modelling and design. Initially they presented practical electromagnetic analysis techniques [18] including the application of symmetry [19] to speed up electromagnetic simulation times and to improve simulation accuracy. Then they presented a CAD parameter extraction technique [20],[21] to produce accurate equivalent circuits. This technique is based on first electromagnetic principles thus providing a physical insight into the extraction process. In this way accurate equivalent circuits can be produced for each individual monoblock structure thus avoiding the "general purpose" equivalent circuits found in the literature. The main advantage of this technique is its suitability for analysing structures of arbitrary geometry and materials. Based on these techniques it was possible to design ceramic monoblock filters for mobile handsets operating in the PCS and UMTS frequency bands [22], [23] Figure 11.

As an example, the inductances and capacitances associated with the filter's cups and the impedances associated with the filter's resonators were determined by numerically solving well established electromagnetic equations in the "field calculator" menu of HFSS. The capacitance per unit length of a 
transmission line is given by $\mathrm{C}=\mathrm{q} / \mathrm{V}$, where the electric charge $\mathrm{q}$ is calculated from the electric flux density $\mathrm{D}$ over a closed surface A as shown in Figure 12.
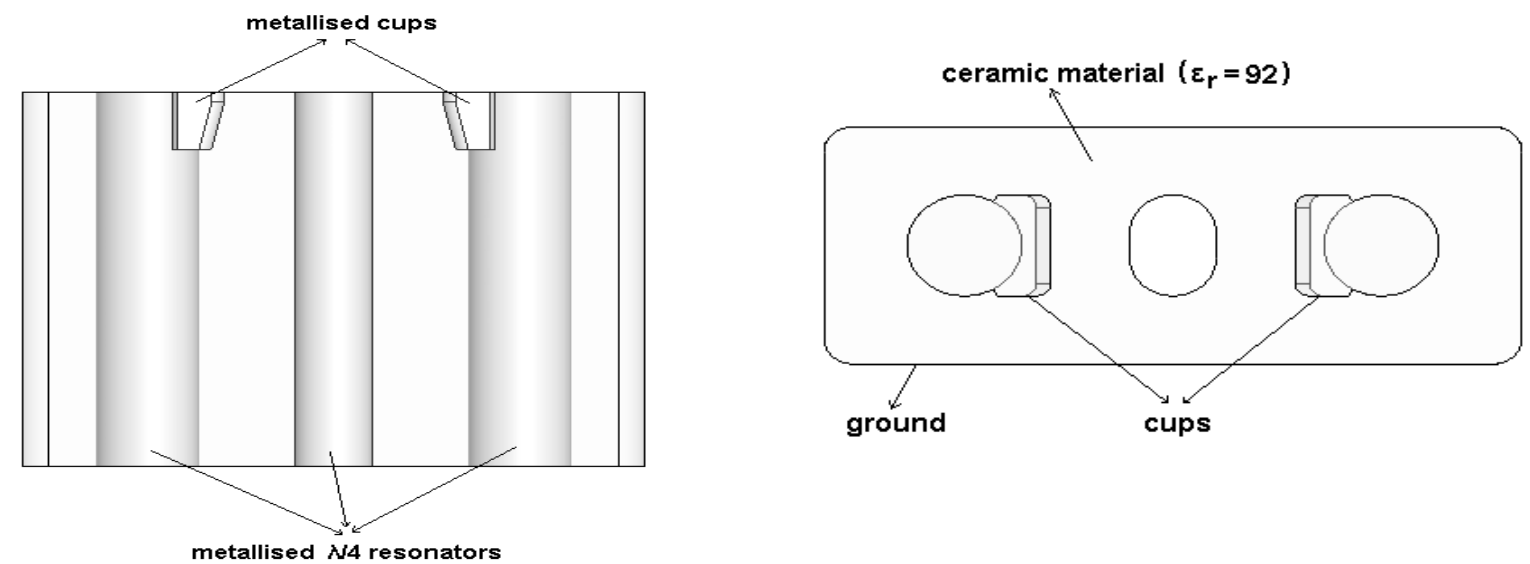

(a)

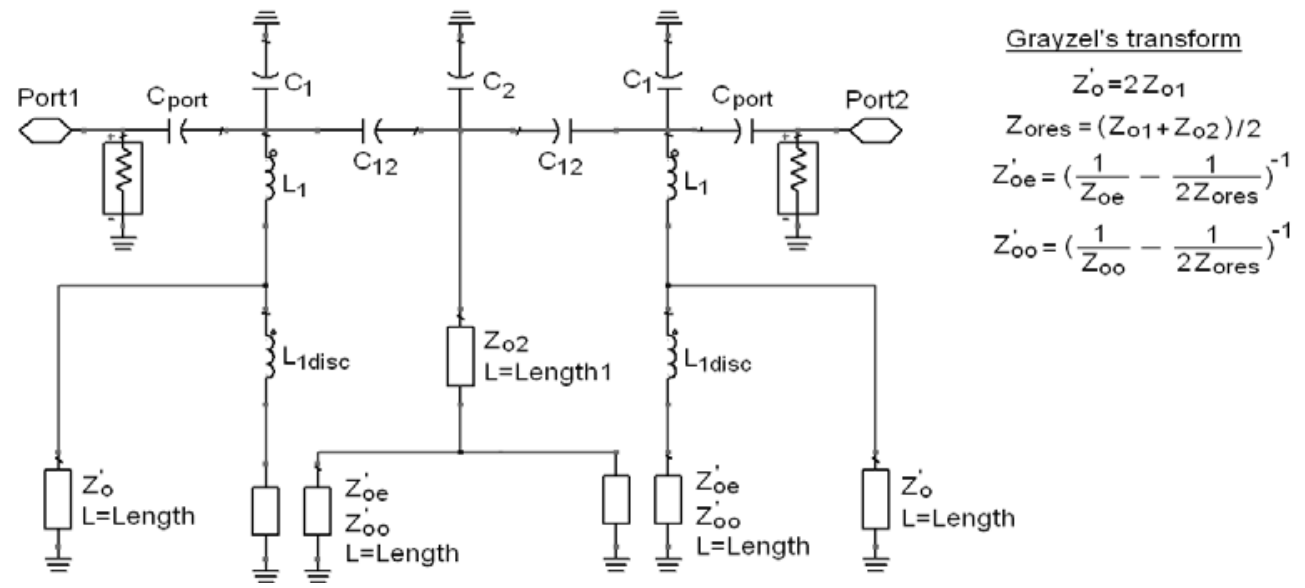

(b)

Figure 11. (a) Ceramic monoblock filter layout. (b) Equivalent circuit [21].

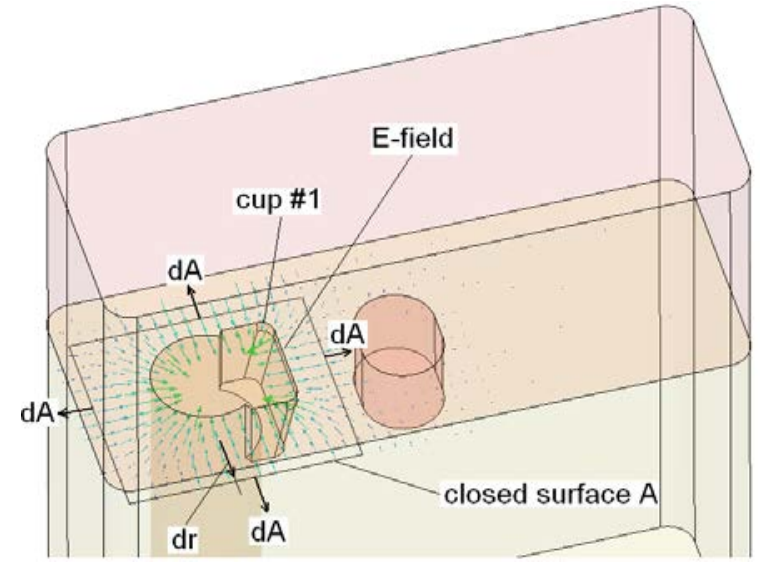

(a)

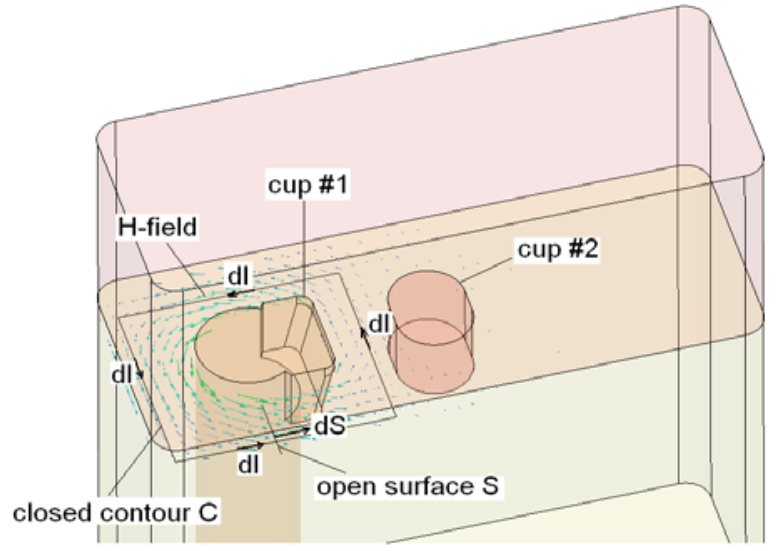

(b)

Figure 12. (a) Extraction of filter's cup capacitance to ground. (b) Extraction of inductances associated with the filter's cups [21]. 


$$
q=\int_{\mathrm{A}} \mathrm{D} \cdot \mathrm{dA}=\int_{\mathrm{A}} \varepsilon \mathrm{E} \cdot \mathrm{dA}
$$

and the voltage $\mathrm{V}$ is evaluated by integrating the electric field $\mathrm{E}$ along a line integral in the $\mathrm{r}$ direction:

$$
V=-\int \mathrm{E} \cdot d r
$$

The inductance per unit length of a transmission line is given by $\mathrm{L}=\Phi / \mathrm{I}$. The magnetic flux $\Phi$ is calculated by integrating the magnetic flux density B normal to an open surface $\mathrm{S}$ in a radial direction:

$$
\Phi=\int_{S} \mathrm{~B} \cdot \mathrm{dS}=\int_{\mathrm{S}} \mu \mathrm{H} \cdot \mathrm{dS}
$$

and the current I is calculated by integrating the magnetic field $\mathrm{H}$ around a closed contour:

$$
I=\int_{C} \mathrm{H} \cdot \mathrm{dl}
$$

\begin{tabular}{|c|c|c|}
\hline Equivalent circuit parameters & Extracted values & Optimised values \\
\hline Cup \#1 (\#3) capacitance to ground: $\mathrm{C}_{1}=\mathrm{C}_{3}$ & $1.8065 \mathrm{pF}$ & $1.5217 \mathrm{pF}$ \\
\hline Cup \#2 capacitance to ground: $\mathrm{C}_{2}$ & $0.4833 \mathrm{pF}$ & $0.2503 \mathrm{pF}$ \\
\hline Cup \#1 (\#3) capacitance to port: $\mathrm{C}_{\text {port }}$ & $1.3454 \mathrm{pF}$ & $0.5933 \mathrm{pF}$ \\
\hline Resonator \#1 (\#3) to cup \#1 (\#3) discontinuity inductance: $\mathrm{L}_{1 \mathrm{disc}}=\mathrm{L}_{3 \mathrm{disc}}$ & $0.05115 \mathrm{nH}$ & $0.0640 \mathrm{nH}$ \\
\hline Resonator \#1 (\#3) characteristic impedance: $\mathrm{Z}_{01}=\mathrm{Z}_{03}$ & 5.9680 Ohms & 7.3994 Ohms \\
\hline Odd-mode characteristic impedance of resonators \#1 and \#2 (\#2 and \#3): $\mathrm{Z}_{0 \mathrm{o}}$ & $5.2680 \mathrm{Ohms}$ & $6.7338 \mathrm{Ohms}$ \\
\hline Transformed resonator \#1 (or \#3) characteristic impedance: $\mathrm{Z}_{0}^{\prime}$ & 11.9360 Ohms & 14.7987 Ohms \\
\hline Transformed even-mode characteristic impedance of resonators \#1 and \#2 (\#2 and \#3): $\mathrm{Z}_{0 \mathrm{e}}^{\prime}$ & 15.3543 Ohms & 22.2189 Ohms \\
\hline Transformed odd-mode characteristic impedance of resonators \#1 and \#2 (\#2 and \#3): $\mathrm{Z}_{0_{0}}^{\prime}$ & $8.9692 \mathrm{Ohms}$ & $11.9740 \mathrm{Ohms}$ \\
\hline
\end{tabular}

The equivalent extracted parameter values are presented in Table 1 . Figure 13 presents the circuit and structural response of the filter.

Table 1. Equivalent Circuit Extracted Parameter Values [21].

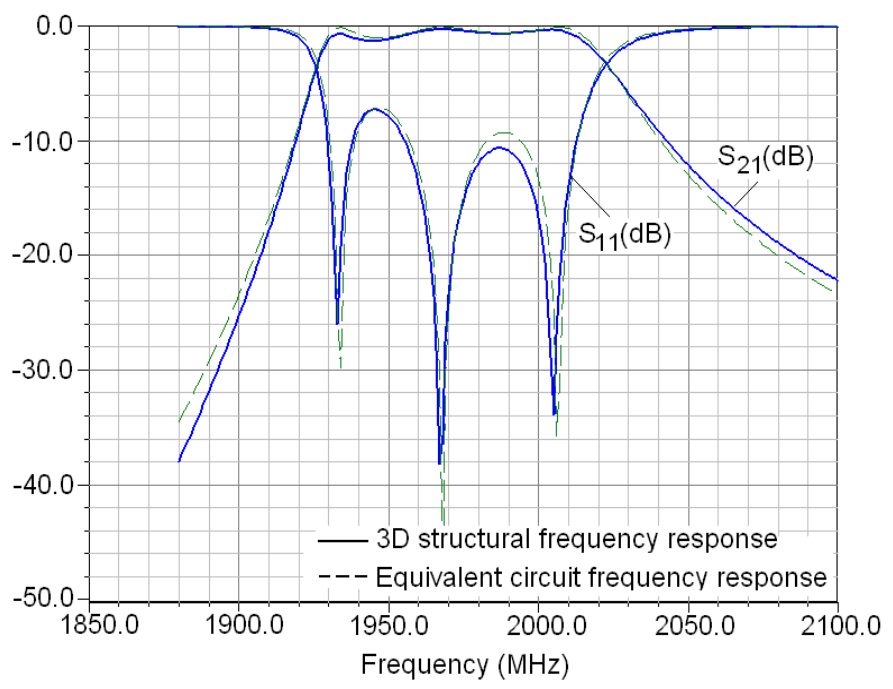

Figure 13. PCS filter structural and equivalent circuit response [21]. 
Based on the techniques described above a duplexer suitable for a mobile handset operating in the UMTS receive and transmit frequency bands was designed [24] Figure 14. Its frequency response is presented in Figure 15. The above work was extended further by applying efficiently the Differential Evolution Algorithm (DEA) combined with the Finite Element Method (FEM) towards the optimal shape design of ceramic microwave filters in order to meet specific requirements [22]. The overall algorithm was implemented by a two-step procedure, which is repeated iteratively. In the first step, for a given set of the design parameters values, the electromagnetic analysis problem is solved using the Ansoft HFSS computational package, which is based on the FEM. In the second step, the DEA updates the values of the design parameters based on their performance in meeting the design specifications.

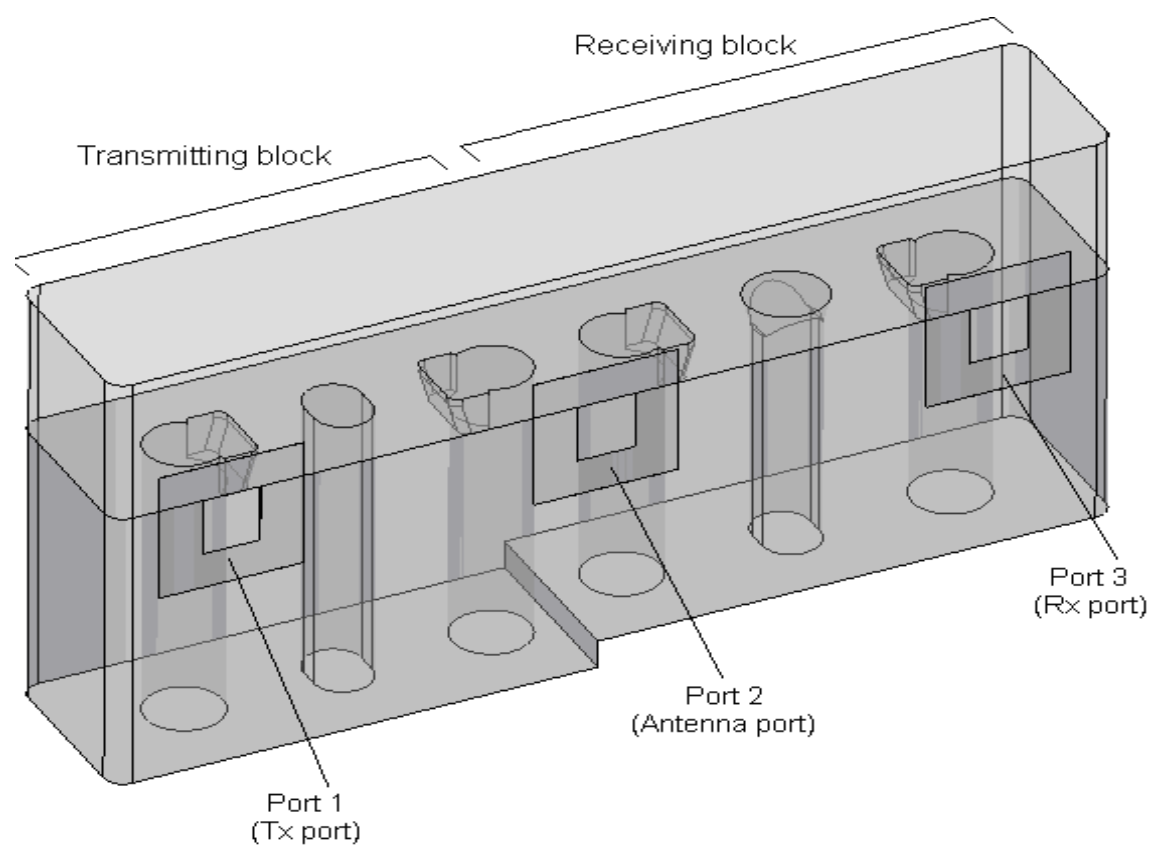

(a)

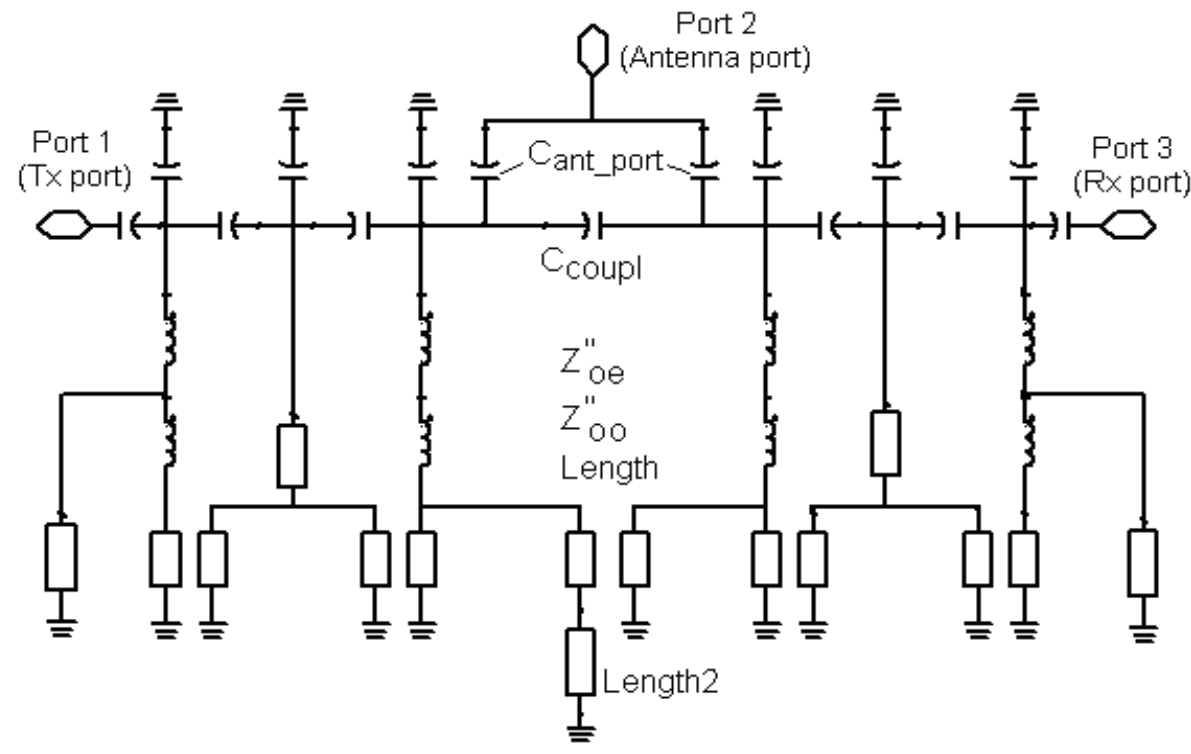

(b)

Figure 14. (a) UMTS ceramic block duplexer layout. (b) Equivalent circuit topology [24]. 


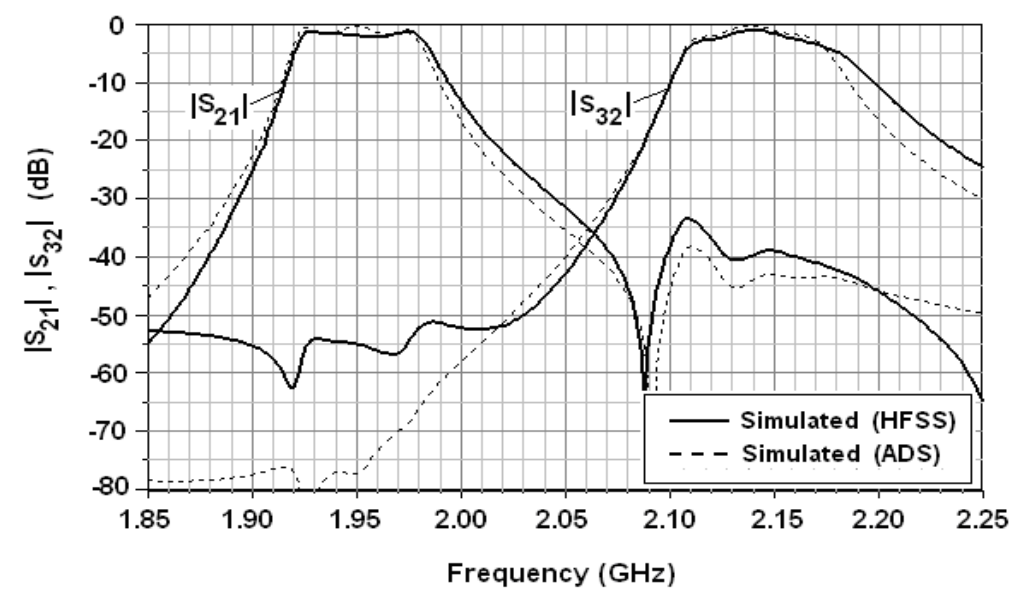

Figure 15. Frequency response of the UMTS duplexer of Figure 14 [24].

\section{CONCLUSION}

An extensive review of the technological developments on ceramic monoblock filters and duplexers over the years is presented in this work. The review of course is not exhaustive but the basic milestones on the design and development of these structures was presented. It was shown that although early designs were based on simulated and measured data, later designs were based on accurate equivalent circuits as well as the use of evolution algorithms for optimal design.

\section{ACKNOWLEDGEMENTS}

The author would like to acknowledge the Research Committee of the Technological and Educational Institute (T.E.I.) of Central Macedonia, Serres, Greece for supporting this work. (Decision SAT/IC/090517-67/10/P/6).

\section{REFERENCES}

[1] U. Rafique, et al., “Bandstop Filter Design for GSM Shielding Using Frequency Selective Surfaces”, International Journal of Electrical and Computer Engineering (IJECE), vol. 2, no.6, pp. 846-850, Dec 2012.

[2] F. Aytouna, et al., “A Novel CPW Low Cost Lowpass Filter Integrating Periodic Structures”, International Journal of Electrical and Computer Engineering (IJECE), vol. 6, no. 3, pp. 1106-1111, June 2016.

[3] A. Boutejdar, et al., "Design and Improvement of a Compact Bandpass Filter using DGS Technique for WLAN and WiMAX Applications”, TELKOMNIKA, vol. 15, no.3, pp. 1137-1144, Sept 2017.

[4] M. A. Sazali et al., " Hybrid Microstrip Diplexer Design for Multi-band WiMAX Application in 2.3 and $3.5 \mathrm{GHz}$ Bands”, International Journal of Electrical and Computer Engineering (IJECE), vol. 8, no. 1, pp. 576-584, Feb 2018.

[5] S. J. Fiedziuszko, et al., "Dielectric Materials, Devices, and Circuits", IEEE Transactions on Microwave Theory and Techniques, vol. 50, no. 3, pp. 706-720, Mar 2002.

[6] I. M. Reaney and D. Iddle, "Microwave Dielectric Ceramics for Resonators and Filters in Mobile Phone Networks”, Journal of the American Ceramic Society, vol. 89, iss. 7, pp. 2063-2072, July 2006.

[7] M. Le Coq, et al., "Miniature microstrip filter using high-permittivity ceramic substrates $\left(\mathrm{e}_{\mathrm{r}}=90\right)$ ", IEEE MTT-S International Microwave Symposium Digest, pp. 1-4, 2011.

[8] E. Kemppinen, et al., "Realization of Integrated Miniature Ceramic Filters for $900 \mathrm{MHz}$ Cellular Mobile Radio Applications”, 17th European Microwave Conference, pp. 175-180, 1987.

[9] Y. Isota, et al., “A Grooved Monoblock Comb-Line Filter Suppressing the Third Harmonics”, IEEE MTT-S International Microwave Symposium Digest, Vol. 1, pp. 383-386, 1987.

[10] H. Matsumoto, et al., "A miniaturized dielectric monoblock band-pass filter for $800 \mathrm{MHz}$ band cordless telephone system”, IEEE MTT-S International Microwave Symposium Digest, Vol. 1, pp. 249-252, 1994.

[11] H. Matsumoto, et al., "A miniaturized dielectric monoblock duplexer matched by the buried impedance transforming circuit”, IEEE MTT-S International Microwave Symposium Digest, Vol. 3, pp. 1539-1542, 1995.

[12] A.J. Kennerley and I.C. Hunter, "Miniature microwave filters using high permittivity ceramics", IEEE MTT-S Symposium on Technology Wireless Applications Digest, pp. 135-139, 1995.

[13] S. Kobayashi and K. Saito, "A miniaturized ceramic bandpass filter for cordless phone systems", IEEE MTT-S International Microwave Symposium Digest, Vol. 2, pp. 391-394, 1995.

[14] Y. Ishikawa, et al., "V band planar type dielectric resonator filter fabricated in ceramic substrate", Topical Symposium on Millimeter Waves, pp. 93-96, 1997. 
[15] T. Uusitupa and J. Loukkola, “On the modelling of ceramic combline RF-filter”, 27th European Microwave Conference, Vol. 2, pp. 1092-1097, 1997.

[16] S.K. Park and J. C. Ziegert, “Ceramic block bandpass filter components for_small_quantity applications”, IEEE Southeastcom '98 Proceedings, pp. 144-147, 1998.

[17] R. S. Kwok and S. J. Fiedziuszko, "Helical ceramic resonator structures”, IEEE MTT-S International Microwave Symposium Digest, Vol. 3, 1999.

[18] S. Tsitsos, et al., "Electromagnetic analysis techniques for 3-D microwave structures using commercial electromagnetic software”, Microwave and Optical Technology Letters, vol. 40, no. 4, pp. 335-339, Feb 2004.

[19] S. Tsitsos, et al., "Application of the symmetry eigenvalue approach to the analysis of a PCS-type ceramic monoblock filter”, International Journal of Electronics, vol. 94, no. 6, pp. 653-661, Jun 2007.

[20] S. Tsitsos, et al., "A new technique for the extraction of equivalent circuit parameters from 3-D monoblock filters", International Journal of RF and Microwave Computer-Aided Engineering, vol. 15, no. 2, pp. 210-217, Mar 2005.

[21] P. Kyriazidis, et al., "Equivalent circuit parameter extraction techniques for a PCS ceramic filter, using commercial electromagnetic software”, $36^{\text {th }}$ European Microwave Conference, 2006, pp. 1159-1162.

[22] S. Tsitsos, et al., "Design of a 3-pole PCS-type monoblock filter using an equivalent circuit approach", $A E \ddot{U}$ International Journal of Electronics and Communications, vol. 60, pp. 638-646, 2006.

[23] P. Kyriazidis and S. Tsitsos, "Design of a UMTS monoblock filter using an equivalent circuit approach", Automated RF and Microwave Measurement Society (ARMMS) Conference, Nov. 2007.

[24] S. Tsitsos, et al., "Efficient CAD design of ceramic block duplexers", International Journal of Electronics Letters, vol. 101, no. 1, pp. 50-60, 2014.

[25] Th. I. Kosmanis, et al., "Optimal design of pcs ceramic microwave filters using the differential evolution algorithm”, ACES Journal, vol. 31, no. 4, pp. 361-365, Apr 2016.

\section{BIOGRAPHY OF AUTHOR}

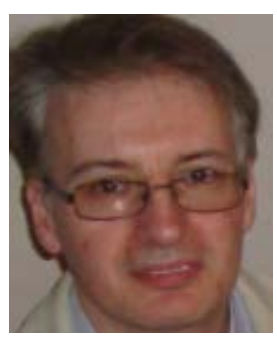

Stelios P. Tsitsos was born in Greece in 1966. He was awarded the Diploma in Electrical and Computer Engineering from the Democritus University of Thrace, Greece, in 1989. In 1991 he was awarded the Master's Degree in Telecommunications Engineering and Digital Electronics from the University of Manchester Institute of Science and Technology (UMIST), UK. In 1994 he was awarded his Ph.D Degree in Microwave Engineering from the same University. From 1996 to 1999 he worked as a Research Associate at UMIST, UK, where he conducted research on the design and optimization of ceramic filters for mobile phones, for TDK Corporation, Japan. From 1999 to 2002 he worked for the Greek Telecommunications Company (OTE) as a Senior Engineer. In 2002 he joined the Department of Computer Engineering of the Technological and Educational Institute of Central Macedonia, Serres, Greece, where he is now a Professor. His research interests include passive and active microwave components and devices for wireless communications and computational electromagnetics. Dr. Tsitsos is a member of the Technical Chamber of Greece, IEEE (Institute of Electrical and Electronics Engineers) and ARMMS (Automated RF and Microwave Measurement Society), UK. 